\title{
Developmental Biology of Oxidant-Producing Enzymes and Antioxidants in the Piglet Intestine
}

\author{
KAREN D. CRISSINGER, MATTHEW B. GRISHAM, AND D. NEIL GRANGER \\ Department of Physiology and Biophysics, Louisiana State University Medical Center, \\ Shreveport, Louisiana 71130-3932
}

\begin{abstract}
The pathogenesis of neonatal necrotizing enterocolitis is unknown, but a possible role for reactive oxygen metabolites has been postulated. We evaluated whether developmental differences exist in the levels of 1) the free radical-generating enzyme xanthine oxidase, 2) granulocyte peroxidase, an index of the resident granulocyte population, 3) free radical-scavenging enzymes (superoxide dismutase, catalase, and glutathione peroxidase), and 4) reduced glutathione, an endogenous antioxidant, in the ileal and colonic mucosa of 1-d-old, 3-d-old, 2-wk-old, and 1-mo-old piglets. We found no xanthine dehydrogenase/oxidase activity in 1-d to 1-mo-old piglets. Mucosal granulocyte peroxidase activity was higher in older animals, indicating that there was an age-dependent infiltration of granulocytes (eosinophils, neutrophils) in the distal bowel. The peroxidase activity per circulating granulocyte, however, did not vary with age. Superoxide dismutase activity was significantly higher in 1-d-old piglets than in all older age groups; glutathione peroxidase activity was significantly lower in 1-d-old animals than that of older age groups. There was no detectable catalase activity in the mucosa when tissue was corrected for catalase activity of blood. Finally, ileal GSH levels were significantly lower in 1-d-old than in 2-wk-old and 1-mo-old animals, whereas colonic reduced glutathione activity did not differ among age groups. In conclusion, the distal bowel of the neonatal piglet appears to have a limited capacity to generate oxidants via xanthine oxidase and resident granulocytes. However, the neonatal piglet intestine has a lower capacity to detoxify hydrogen peroxide than that of older animals. (Pediatr Res 25: 612-616, 1989)
\end{abstract}

\section{Abbreviations}

SOD, superoxide dismutase

CAT, catalase

GSH, reduced glutathione

GSH Px, glutathione peroxidase

A substantial body of experimental data supports the hypothesis that reactive oxygen metabolites mediate the microvascular and mucosal permeability changes observed after reperfusion of the ischemic intestine in adult animals (1-5). The two major sources of oxygen-derived free radicals in the postischemic intestine are xanthine oxidase (1-3) and the NADPH-oxidase asso-

Received November 21, 1988; accepted February 1, 1989.

Correspondence and reprint requests Karen D. Crissinger, M.D., Ph.D., Department of Pediatrics, Louisiana State University Medical Center, P.O. Box 33932 Shreveport, LA 71130-3932.

Supported by Grant HL-26441 from NIH. K.D.C. was supported by a National Research Service Award DK-08056 from NIH. ciated with phagocytic leukocytes (neutrophils, eosinophils, and macrophages) (4). Xanthine oxidase and activated phagocytes produce large quantities of cytotoxic oxidants including superoxide, hydrogen peroxide, and possibly hydroxyl radicals (6). Cellular enzymatic defense mechanisms against these oxidants include SOD, which dismutates the superoxide anion to hydrogen peroxide and oxygen; and CAT and GSH Px, which detoxify hydrogen peroxide (7). Another important oxidant defense is GSH, which serves both as a cosubstrate for the GSH Pxcatalyzed decomposition of hydrogen peroxide, and as a free radical scavenger (8).

The pathogenesis of neonatal necrotizing enterocolitis is unknown, but infectious agents/immunologic factors, enteral alimentation, and mesenteric ischemia are fequently invoked as primary initiators of the disease $(9,10)$. A role for reactive oxygen metabolites in the etiology of necrotizing enterocolitis has recently been postulated $(11-14)$, with xanthine oxidase implicated as the primary source of oxygen radical production in this disease of the distal bowel $(11,13,14)$. Thus, the objective of this study was to determine whether the capacity of the distal piglet intestine to produce and protect against oxygen-derived free radicals changes significantly during development.

\section{MATERIALS AND METHODS}

Hampshire/Yorkshire piglets of either sex were divided among 1-d-old $(n=5,1.1 \pm 0.1 \mathrm{~kg}), 3$-d-old $(n=5,1.5 \pm 0.1 \mathrm{~kg}), 2$ wk-old $(n=5,5.0 \pm 0.2 \mathrm{~kg})$, and 1-mo-old $(n=6,6.1 \pm 0.4 \mathrm{~kg})$ animals. One young adult pig (7-mo-old, $36.8 \mathrm{~kg}$ ), in which intestinal tissue could be harvested in an identical manner to that of the younger piglets, was used as an adult comparison. The 1-d-old piglets were not allowed to nurse before the experiment. All other piglets were fasted for 14 (3-d-olds) or 24 (all older piglets) before the experiment. After intramuscular injection of ketamine hydrochloride $(20 \mathrm{mg} / \mathrm{kg})$ and xylazine $(2 \mathrm{mg} /$ $\mathrm{kg}$ ), the animals were anesthetized with intravenous sodium pentobarbital $(15 \mathrm{mg} / \mathrm{kg})$.

Surgical procedure/sample collection. The animals were artificially ventilated via a tracheostomy. A cannula was inserted into the left carotid artery to monitor blood pressure and obtain blood samples. A total of $6 \mathrm{~mL}$ of blood was removed, one-half frozen for later biochemical assay and one-half used for isolation of circulating neutrophils. The abdomen was then opened through a midline incision. Segments of the distal ileum and proximal spiral colon were removed and rinsed with isotonic saline. The mucosa/submucosa was separated from the muscularis/serosa via blunt dissection, snap-frozen in liquid nitrogen, and stored at $-70^{\circ} \mathrm{C}$ until assayed. The animals were killed with an intravenous injection of pentobarbital.

Isolation of circulating granulocytes. Polymorphonuclear leukocytes (eosinophils, neutrophils) were isolated by a modification (15) of the method of Markert et al. (16). Heparinized whole blood was mixed with an equal vol of $3 \%$ (wt/vol) dextran (mol 
wt 400000 ) in PBS ( $\left.\mathrm{pH} 7.4,37^{\circ} \mathrm{C}\right)$ in a plastic syringe. The red blood cells were allowed to settle for $20 \mathrm{~min}$ at room temperature; the leukocyte-rich supernatant was then removed and centrifuged (10 min, $2000 \mathrm{rpm}, 4^{\circ} \mathrm{C}$ ). After discarding the supernatant, the pellet was resuspended in ice-cold hypotonic buffer containing 10-mM $\mathrm{KHCO}_{3}, 154-\mathrm{mM} \mathrm{NH}_{4} \mathrm{Cl}, 0.14-\mathrm{mM}$ EDTA (pH 7.2) and incubated at $4^{\circ} \mathrm{C}$ for $10 \mathrm{~min}$ to lyse contaminating erythrocytes. The suspension was then centrifuged $(10 \mathrm{~min}, 2000 \mathrm{rpm}$, $4^{\circ} \mathrm{C}$ ) and the pellet was resuspended in cold PBS and placed on ice. An aliquot of cells was mixed with $3 \%$ acetic acid, stained with $0.01 \%$ crystal violet, and the leukocytes were counted. The cells were suspended in $1 \%$ hexadecyltrimethylammonium bromide at a concentration of $10^{6}$ granulocytes $/ \mathrm{mL}$ and frozen at $-70^{\circ} \mathrm{C}$.

Biochemical Assays. Xanthine dehydrogenase/oxidase activity. Activity was determined in the mucosa/submucosa by the method of Waud and Rajagopalan (17). Tissue samples (on ice) were homogenized $(10 \% \mathrm{wt} / \mathrm{vol})$ in $50 \mathrm{mM}$ potassium phosphate buffer ( $\mathrm{pH} 7.8$ ), containing 0.25-M sucrose, 1-mM EDTA, $0.2-$ $\mathrm{mM}$ phenylmethylsulphonyl fluoride and $0.5-\mathrm{mM}$ dithiothreitol, centrifuged $\left(20 \mathrm{~min}, 10000 \mathrm{rpm}, 4^{\circ} \mathrm{C}\right)$, and the supernatant was applied to a Sephadex G-25 column to remove low mol wt inhibitors. The enzyme was assayed using xanthine as the substrate in $50-\mathrm{mM}$ phosphate buffer $(\mathrm{pH} \mathrm{7.8)}$, in the presence of NAD to measure total xanthine dehydrogenase + xanthine oxidase activity, and in the absence of NAD to measure only xanthine oxidase activity. Enzyme-catalyzed uric acid formation was then monitored spectrophotometrically (Perkin-Elmer Lambda 3B UV/Vis Spectrometer, Norwalk, CT) at $295 \mathrm{~nm}$, with activity expressed as $\mathrm{mU} / \mathrm{g}$ dry wt of tissue. Activity of $1 \mathrm{U}$ was defined as the amount of enzyme present that produces 1 $\mu \mathrm{mol}$ of urate $/ \mathrm{min}$ at $25^{\circ} \mathrm{C}$.

Granulocyte peroxidase activity. Peroxidase activity was determined by the method of Grisham et al. (4) in which samples of mucosa/submucosa (on ice) were homogenized (10\% wt/vol) in $20-\mathrm{mM}$ potassium phosphate buffer (pH 7.4) and centrifuged $\left(15 \mathrm{~min}, 10000 \mathrm{rpm}, 4^{\circ} \mathrm{C}\right.$ ) to pellet the insoluble cellular debris. The supernatant, which contained $<5 \%$ of total peroxidase activity, was discarded. The pellet was then rehomogenized in 50 $\mathrm{mM}$ potassium phosphate buffer ( $\mathrm{pH}$ 6.0) containing $0.5 \%$ hexadecyltrimethylammonium bromide and 10-mM EDTA. After twice freezing and thawing, the peroxidase activity was assessed by measuring the hydrogen peroxide-dependent oxidation of 3 $3^{\prime}-5-5^{\prime}$-tetramethylbenzidine at $37^{\circ} \mathrm{C}(18)$. Enzyme activity of 1 $\mathrm{U}$ was defined as the amount of peroxidase present that produced a change in absorbance $/ \mathrm{min}$ of 1.0 at $655 \mathrm{~nm}$.

For measurement of peroxidase activity in circulating granulocytes, cells were thawed and made $2-\mathrm{mM}$ with respect to EDTA. Cells were then homogenized, twice frozen and thawed, and assayed for peroxidase activity as described above for tissue samples.

SOD activity. Total SOD activity was measured using the method of McCord and Fridovich (19), in which samples of mucosa/submucosa or whole blood (on ice) were homogenized

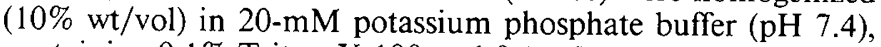
containing $0.1 \%$ Triton $\mathrm{X}-100$ and $0.1 \mathrm{mM}$ EDTA, and centrifuged $\left(20 \mathrm{~min}, 12000 \mathrm{rpm}, 4^{\circ} \mathrm{C}\right)$. The supernatant was saved for measurement of SOD, CAT, and GSH Px activities and $\mathrm{Hb}$ concentration. SOD in the clarified supernatant was monitored for its ability to inhibit superoxide-dependent cytochrome $\mathrm{c}$ reduction. Superoxide was produced by the reaction of xanthine oxidase with xanthine in $50-\mathrm{mM}$ potassium phosphate buffer (pH 7.8) containing $0.1-\mathrm{mM}$ EDTA and $15 \mu \mathrm{g} / \mathrm{mL}$ of catalase. Sodium cyanide $(10 \mu \mathrm{M})$ was included in the reaction vol to inhibit cytochrome oxidase. SOD of $1 U$ was defined as the amount of enzyme present that inhibits the rate of cytochrome c reduction by $50 \%$ at $25^{\circ} \mathrm{C}$.

Catalase activity. CAT activity in the clarified supernatant of tissue or whole blood was determined according to the method of Aebi (20), in which the catalytic activity was followed by the decrease in absorbance at $240 \mathrm{~nm}$ in the presence of $10-\mathrm{mM}$ hydrogen peroxide. Catalase activity of $1 \mathrm{U}$ was defined as the amount of enzyme present that decomposes one $\mu \mathrm{mol}$ of hydrogen peroxide $/ \mathrm{min}$ at $25^{\circ} \mathrm{C}$.

Glutathione peroxidase activity. GSH Px activity was assessed by the method of Paglia and Valentine (21), in which the clarified supernatant of tissue or whole blood was monitored for its ability to catalyze the oxidation of glutathione by hydrogen peroxide using the glutathione reductase-recycling assay. NADPH oxidation was used to follow the reaction and was monitored by the decrease in absorbance at $340 \mathrm{~nm}$. Sodium azide $(0.1 \mathrm{mM})$ was included in all assays to inhibit endogenous catalase activity. Activity of $1 \mathrm{U}$ was defined as the amount of enzyme present that catalyzed the oxidation of $1 \mu \mathrm{mol} / \mathrm{min}$ of NADPH.

Reduced glutathione content. GSH (acid-soluble sulfhydryl) content of intestinal mucosa/submucosa was measured using the method of Sedlak and Lindsey (22). Samples were homogenized (10\% wt/vol) in 20-mM EDTA (pH 4.7), an aliquot of tissue homogenate added to ice cold $10 \%$ trichloroacetic acid and vortexed for $15 \mathrm{~s}$. Protein precipitate was removed by centrifugation, the supernatant was neutralized by the addition of a small aliquot of $10-\mathrm{N} \mathrm{NaOH}$, and GSH content was determined by its reaction with 5-5'-dithiobis-(2-nitrobenzoic acid) to yield the yellow chromophore, 5-thio-2-nitrobenzoic acid (TNB), assuming an extinction coefficient of $13600 \mathrm{M}^{-1} \mathrm{~s}^{-1}$ for TNB at $412 \mathrm{~nm}$.

$\mathrm{Hb}$ determination. $\mathrm{Hb}$ (cyanomethemoglobin) concentration in the clarified supernatant of homogenized tissue and of whole blood was determined by the method of Tentori and Salvati (23) using Drabkins reagent. Tissue and whole blood hemoglobin concentrations were used to correct tissue SOD, CAT, and GSH $P x$ activities for the activities contained in whole blood.

Data analysis. All values are expressed as mean \pm SEM. For each enzyme/antioxidant measured, a two-factor-ANOVA was performed, followed by Duncan multiple range tests (24) if the
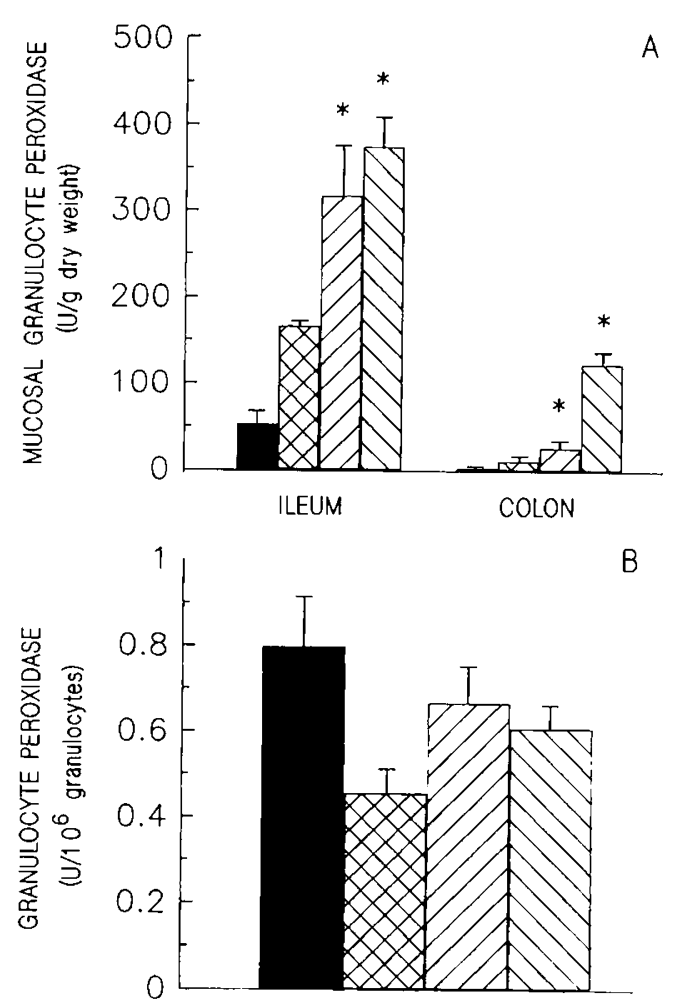

Fig. 1. Granulocyte peroxidase activity in ileal and colonic mucosa/ submucosa $(A)$ and circulating granulocytes $(B)$ of 1-d-old $(\square), 3$-d-old $(\bigotimes)$, 2-wk-old $(\mathscr{C})$, and 1-mo-old $(\mathbb{\mathbb { S }})$ piglets; * indicates $p<0.05$ vs. 1-dold values. 
ANOVA revealed differences among age groups. Differences were considered significant at $p<0.05$.

\section{RESULTS}

No xanthine oxidase activity was detected in the ileal or colonic mucosa/submucosa of piglets from $1 \mathrm{~d}$ to 1 mo of age; however, in the 7-mo-old young adult pig, small amounts of xanthine oxidase activity were present in both ileum $(61 \mathrm{mU} / \mathrm{g}$ dry $\mathrm{wt})$ and colon (66 mU/g dry wt).

The activity of granulocyte peroxidase in the ileum and colon of the developing piglet increased markedly as the piglet matured (Fig. 1 $A$ ), whereas the amount of peroxidase per granulocyte did not significantly vary with age (Fig. $1 B$ ).

The activities of superoxide dismutase and glutathione peroxidase in the ileum and colon are illustrated in Figures 2 and 3, respectively. The intestine of $1-d-o l d$ piglets had a greater ability to dismutate superoxide to hydrogen peroxide and oxygen than the intestine of older piglets (Fig. 2), yet it had a lower capacity to detoxify hydrogen peroxide (Fig. 3). Significant levels of intestinal catalase activity were not present in any age group after subtracting the activity contributed by whole blood trapped within the tissue. Activities of SOD, CAT, and GSH Px in whole blood are shown in Table 1. Table 2 lists the $\mathrm{Hb}$ content in tissue and whole blood, and the wet/dry wt ratio for the intestinal tissue.

Reduced glutathione was significantly lower in the ileum of 1d-old than 2-wk-old and 1-mo-old piglets, whereas levels of GSH in the colon were not significantly different among age groups (Fig. 4).

Except for xanthine oxidase, the results of all assays on tissues

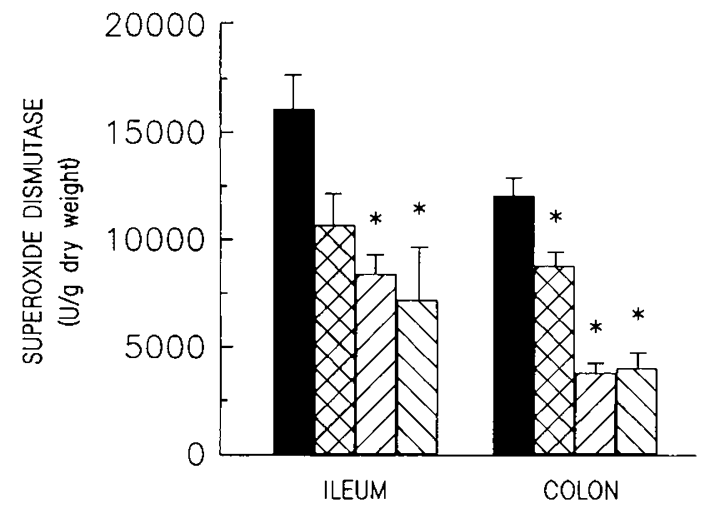

Fig. 2. Superoxide dismutase activity in ileal and colonic mucosa/

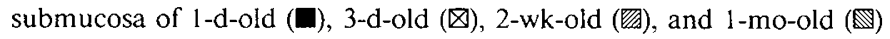
piglets; ${ }^{*}$ indicates $p<0.05$ vs. 1-d-old values.

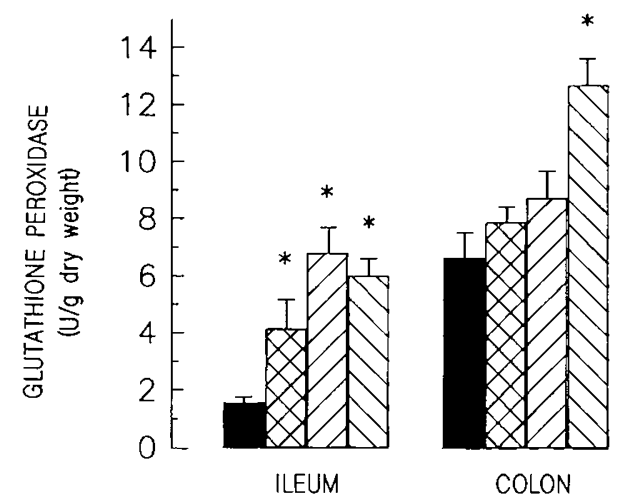

Fig. 3. Glutathione peroxidase activity in ileal and colonic mucosa/

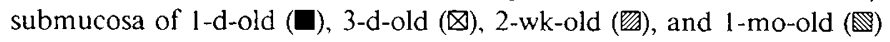
piglets: * indicates $p<0.05$ vs. 1 -d-old values.
Table 1. Whole blood superoxide dismutase, catalase, and glutathione peroxidase activity

\begin{tabular}{|c|c|c|c|}
\hline & $\begin{array}{c}\text { SOD } \\
(\mathrm{U} / \mathrm{mg} \mathrm{Hb})\end{array}$ & $\begin{array}{c}\text { CAT } \\
\text { (U/mg Hb) }\end{array}$ & $\begin{array}{c}\text { GSH PX } \\
(\mathrm{mU} / \mathrm{mg} \mathrm{Hb})\end{array}$ \\
\hline $1 \mathrm{~d}$ & $4.3 \pm 0.06$ & $126.5 \pm 9.4$ & $9.5 \pm 0.5$ \\
\hline $3 d$ & $2.8 \pm 0.06$ & $126.4 \pm 6.3$ & $12.0 \pm 0.5$ \\
\hline $2 w k$ & $3.5 \pm 0.2$ & $188.8 \pm 13.3$ & $11.0 \pm 1.9$ \\
\hline $1 \mathrm{mo}$ & $6.0 \pm 0.4$ & $147.0 \pm 7.7$ & $8.5 \pm 1.1$ \\
\hline
\end{tabular}

Table 2. Whole blood and tissue $\mathrm{Hb}$ and tissue wet/dry wt ratios

\begin{tabular}{lcccc}
\hline & $1 \mathrm{~d}$ & $3 \mathrm{~d}$ & $2 \mathrm{wk}$ & $1 \mathrm{mo}$ \\
\hline Hb $(\mathrm{mg} / \mathrm{mL})$ & & & & \\
$\quad$ Whole blood & $11.3 \pm 0.8$ & $7.9 \pm 0.4$ & $7.6 \pm 0.4$ & $10.5 \pm 1.0$ \\
Ileum & $0.90 \pm 0.09$ & $0.77 \pm 0.04$ & $0.91 \pm 0.04$ & $1.2 \pm 0.20$ \\
Colon & $1.1 \pm 0.15$ & $0.84 \pm 0.19$ & $1.1 \pm 0.13$ & $1.3 \pm 0.10$ \\
$\begin{array}{c}\text { Wet:dry wt } \\
\text { Ileum }\end{array}$ & $5.4 \pm 0.2$ & $5.0 \pm 0.1$ & $5.3 \pm 0.05$ & $5.4 \pm 0.1$ \\
\hline
\end{tabular}

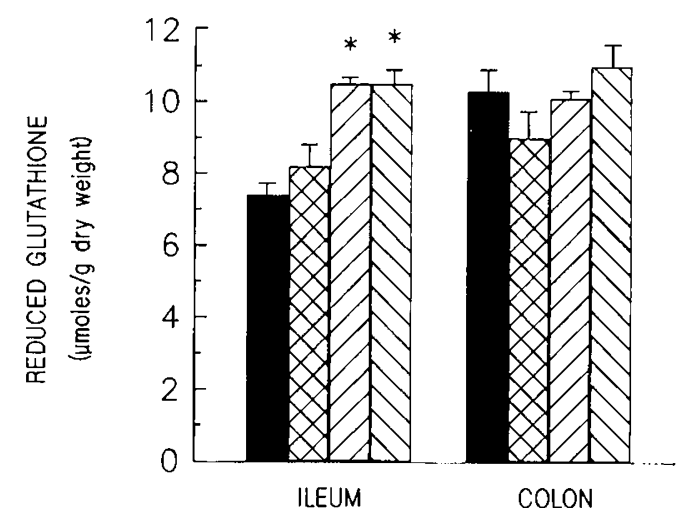

Fig. 4. Reduced glutathione content in ileal and colonic mucosa/

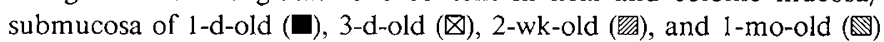
piglets; * indicates $p<0.05$ vs. 1 -d-old values.

derived from the young adult pig were directionally consistent with data obtained from 1-mo-old animals.

\section{DISCUSSION}

Reactive oxygen metabolites play an important role in normal cellular metabolism, most notably as intermediates in mitochondrial and microsomal electron-transport systems (8). More than $90 \%$ of the molecular oxygen consumed by most cells is reduced by the mitochondrial electron transport chain to form water, with the remaining oxygen metabolized to form reactive oxygen species. Under normal conditions, tissues are protected from these oxygen-derived free radicals by the action of certain antioxidant enzymes and scavengers. In adult animals, the digestive system is particularly well-endowed with the enzymatic machinery capable of generating significant quantities of reactive oxygen metabolites. For example, in most species the intestine and liver are the richest sources of xanthine oxidase (25), an enzyme that catalyzes the production of both superoxide anion and hydrogen peroxide. Xanthine oxidase activity in the small intestine is primarily located within the mucosa, with a gradient of activity from villus tip to base (26). In addition, the intestine contains a large resident population of phagocytic cells (neutrophils, eosinophils, macrophages), which, when activated, produce considerable quantities of superoxide, hydrogen peroxide, and hypochlorous acid (27). Oxidants generated by either xanthine oxidase or activated phagocytes can injure cells by a variety of mechanisms. 
These include lipid peroxidation, degradation of the extracellular matrix, protein and carbohydrate decomposition, and DNA strand breakage (8). Nonetheless, the intestinal epithelium is protected by the presence of certain enzymes such as superoxide dismutase, glutathione peroxidase, reduced glutathione, and $\alpha$ tocopherol (28-31).

A large body of experimental data supports a role for oxygenderived free radicals in the pathogenesis of ischemia/reperfusion injury in the intestine of adult animal models (1-5). Based on these studies and the postulated role of mesenteric ischemia as a factor in the pathogenesis of necrotizing enterocolitis, reactive oxygen metabolites have been suggested as etiologic factors in development of this disease (11-14). Premature infants are exposed to numerous hypoxic stresses, which, theoretically, may lead to the formation of hypoxanthine from the metabolism of ATP, and the conversion of xanthine dehydrogenase to xanthine oxidase. On improvement of oxygenation, xanthine oxidase may catalyze the conversion of hypoxanthine to urate and superoxide anion $(11,14)$. This scheme assumes that xanthine dehydrogenase/oxidase is present in the neonatal intestine.

Our study does not support a role for xanthine oxidase as a source of reactive oxygen metabolites in the terminal ileum and colon of the developing piglet. Although present in adult hogs, the total absence of any xanthine dehydrogenase/oxidase activity in the developing animal precludes its role in intestinal ischemia/ reperfusion injury in young swine. Xanthine oxidase activity does appear to be present, however, in the intestine of fetal and neonatal rats, but at a 2- to 3-fold lower level than that present in adult animals (12). It should be noted that adult levels of xanthine dehydrogenase/oxidase activity in the rat are quite high (405-470 mU/g wet wt), compared to other species (32), including swine $(12 \mathrm{mU} / \mathrm{g}$ wet wt; this study). Significant levels of xanthine dehydrogenase/oxidase have been measured in ileum (98 $\mathrm{mU} / \mathrm{g}$ wet wt) and colon $(19 \mathrm{mU} / \mathrm{g}$ wet $\mathrm{wt})$ in adult humans (Crissinger KD, unpublished data). It is unknown, however, whether significant xanthine dehydrogenase/oxidase activity exists in the intestinal mucosa of premature and newborn infants. If the human neonate is similar to newborn swine with respect to xanthine oxidase activity, then it is less likely that oxidants play a role in the pathogenesis of necrotizing enterocolitis.

The significantly lower level of granulocyte peroxidase activity in the intestine of the newborn piglet, as compared to older age groups, also does not support the postulation that the newborn piglet intestine is more vulnerable to oxygen radical-induced injury than that of older animals. This lower number of resident granulocytes in the mucosa does not, however, preclude the possibility of a role for injury induced by granulocytes which may migrate into the tissue during ischemic or other stresses.

The results obtained in this study also suggest that the neonatal piglet intestine is predisposed to hydrogen peroxide-induced cell injury due to the absence of catalase, coupled with the low glutathione peroxidase activity, and the high basal superoxide dismutase activity. Because the product of SOD-catalyzed dismutation of superoxide is hydrogen peroxide and oxygen, one would expect higher fluxes of hydrogen peroxide within the neonatal piglet enterocyte than in that of older animals, based on the high basal superoxide dismutase activity in newborn piglets. Several studies have demonstrated that hydrogen peroxide is more cytotoxic than superoxide toward various types of cultured cells (33-37). This observation may be explained by differences in the stability, chemical reactivity, and lipophilicity of these oxidants. For example, superoxide rapidly dismutates at neutral $\mathrm{pH}$ to form hydrogen peroxide and oxygen, whereas hydrogen peroxide, a stable and lipophilic compound, readily gains access to the intracellular compartment. Once within the cell, hydrogen peroxide interacts with iron to form a more reactive free radical, which in turn initiates cell injury $(33,34)$. Thus, if the neonatal piglet intestine is exposed to a source of superoxide or hydrogen peroxide (e.g. from xanthine oxidase found in milk), the level of antioxidants may be insufficient to provide protection against hydrogen peroxide-induced cellular injury.

In conclusion, the distal ileum and colon of the neonatal piglet has a limited capacity to generate oxidants via xanthine oxidase and resident granulocytes within the mucosa/submucosa. One may speculate that if these findings hold true for the premature infant, the generation of oxygen-derived free radicals within the distal bowel appears unlikely to play a role in necrotizing enterocolitis. Should the neonatal piglet intestine be exposed to other sources of hydrogen peroxide, however, its capacity to detoxify this reactive oxygen metabolite is minimal.

\section{REFERENCES}

1. Granger DN, Hoellwarth ME, Parks DA 1986 Ischemia-reperfusion injury: role of oxygen-derived free radicals. Acta Physiol Scand (suppl)548:47-63

2. Granger DN, McCord JM, Parks DA, Hoellwarth ME 1986 Xanthine oxidase inhibitors attenuate ischemia-induced vascular permeability changes in the cat intestine. Gastroenterology 90:80-84

3. Parks DA, Granger DN, Bulkley GB, Shah AK 1985 Soybean trypsin inhibitor attenuates ischemic injury to the feline small intestine. Gastroenterology 89:6-12

4. Grisham MB, Hernandez LA, Granger DN 1986 Xanthine oxidase and neutrophil infiltration in intestinal ischemia. Am J Physiol 251:G567-G574

5. Hernandez LA, Grisham MB, Twohig B, Arfors KE, Harlan JM, Granger DN 1987 Role of neutrophils in ischemia-reperfusion-induced microvascular injury. Am J Physiol 253:H699-H703

6. Grisham MB, McCord JM 1986 Chemistry and cytotoxicity of reactive oxygen metabolites. In: Taylor AE, Matalon S, Ward PA (eds) Physiology of Oxygen Radicals. American Physiological Society, Baltimore, pp 1-18

7. Marklund SL, Westman NG, Lundgren E, Roos G 1982 Copper- and zinccontaining superoxide dismutase, manganese-containing superoxide dismutase, catalase, and glutathione peroxidase in normal and neoplastic human cell lines and normal human tissues. Cancer Res 42:1955-1961

8. Freeman BA, Crapo JD 1982 Free radical and tissue injury. Lab Invest 47:412426

9. Kliegman RM and Fanaroff AA 1984 Necrotizing enterocolitis. N Engl J Med 310:1093-1103

10. Holzman IR, Brown DR 1986 Necrotizing enterocolitis: a complication of prematurity. Semin Perinatol 10:208-216

11. Saugstad OD 1988 Hypoxanthine as an indicator of hypoxia: its role in health and disease through free radical production. Pediatr Res 23:143-150

12. Engelhardt EL, Beggs JC, Neu J 1987 Maturation of antioxidant enzymes in rat small intestine: lack of glucocorticoid stimulation. J Pediatr 111:459-463

13. Dalsing MC, Sieber P, Grosfield JL, Hasewinkel J, Hull M, Weber 1983 Ischemic bowel: the protective effect of free-radical anion scavengers. J Pediatr Surg 18:360-364

14. Parks DA, Bulkley GB, Granger DN 1983 Role of oxygen-derived free radicals in digestive tract diseases. Surgery $94: 415-422$

15. Grisham MB, Engerson TD, McCord JM, Jones HP 1985 A comparative study of neutrophil purification and function. J Immunol Methods 82:315-320

16. Markert M, Andrews PC, Babior BM 1984 Measurement of $\mathrm{O}_{2}$ production by human neutrophils: the preparation and assay of NADPH oxidase-containing particles from human neutrophils. Methods Enzymol 105:358-364

17. Waud WR, Rajagopalan KV 1976 Purification and properties of the $\mathrm{NAD}^{+}$dependent (type D) and $\mathrm{O}_{2}$-dependent (type $\mathrm{O}$ ) forms of rat liver xanthine dehydrogenase. Arch Biochem Biophy 172:354-364

18. Suzuki K, Ota H, Sasagawa S, Sakatani T, Fujikura T 1983 Assay method for myeloperoxidase in human polymorphonuclear leukocytes. Anal Biochem 132:345-352

19. McCord JM, Fridovich I 1969 Superoxide dismutase: an enzymic function for erythrocuprein (hemocuprein). J Biol Chem 244:6049-6055

20. Aebi H 1984 Catalase in vitro. Methods Enzymol 105:121-126

21. Paglia DE, Valentine WN 1967 Studies on the quantitative and qualitative characterization of erythrocyte glutathione peroxidase. J Lab Clin Med 70:158-169

22. Sedlak J, Lindsay RH 1968 Estimation of total, protein-bound, and nonprotein sulfhydryl groups in tissue with Ellman's reagent. Anal Biochem 25:192-205

23. Tentori L, Salvati AM 1981 Hemoglobinometry in human blood. Methods Enzymol 76:707-715

24. Keppel G 1982 Design and Analysis. Prentice-Hall, Inc, Englewood Cliffs, NJ, 186-207

25. Batelli MG, Della Corte E, Stirpe F 1972 Xanthine oxidase type d (dehydrogenase) in the intestine and other organs of the rat. Biochem J 126:747-749

26. Pickett JP, Pendergrass RE, Bradford WD, Elchlepp JG 1970 Localization of xanthine oxidase in rat duodenum: fixation of sections instead of blocks. Stain Technol 45:35-36

27. Granger DN, Hernandez LA, Grisham MB 1986 Reactive oxygen metabolites: mediators of cell injury in the digestive system. Viewpoints Digest Dis 18:1316

28. Marklund SL 1985 Superoxide dismutase isoenzymes in tissues and plasma from New Zealand black mice, nude mice and normal BALB/c mice. Mutat Res 148:129-134 
29. Hartz JW, Funakoshi S, Deutsch HF 1973 The levels of superoxide dismutase and catalase in human tissues as determined immunochemically. Clin Chim Acta 46:125-132

30. Stahlberg MR, Hietanen E, Maki M 1988 Mucosal biotransformation rates in the small intestine of children. Gut 29:1058-1063

31. Ogasawara T, Hoensch H, Ohnhaus EE 1985 Distribution of glutathione and its related enzymes in small intestinal mucosa of rats. Arch Toxicol (suppl)8:110-112

32. Parks DA, Granger DN 1986 Xanthine oxidase: biochemistry, distribution and physiology. Acta Physiol Scand (suppl)548:87-99

33. Rubin R, Farber JL 1984 Mechanisms of the killing of cultured hepatocytes by hydrogen peroxide. Arch Biochem Biophys 228:450-459
34. Gannon DE, Varani J, Phan SH, Ward JH, Kaplan J, Till GO, Simon RH Ryan US, Ward PA 1987 Source of iron in neutrophil-mediated killing of endothelial cells. Lab Invest 57:37-44

35. Zigler JS, Jernigan HM, Garland D, Reddy VN 1985 The effects of "oxygen radicals" generated in the medium on lenses in organ culture: inhibition of damage by chelated iron. Arch Biochem Biophys 241:163-172

36. Simon RH, Scoggin CH, Patterson D 1981 Hydrogen peroxide causes the fatal injury to human fibroblasts exposed to oxygen radicals. J Biol Chem 256:7181-7186

37. Hiraishi H, Terano A, Ota S, Ivey KJ, Sugimoto T 1987 Oxygen metaboliteinduced cytotoxicity to cultured rat gastric mucosal cells. Am J Physiol 253:G40-G48 